\title{
¿Egoístas o altruistas? Un experimento social para fomentar el comportamiento cooperativo en el mercado*
}

\author{
Selfish or altruistic? A social experiment to promote cooperative behavior in the \\ marketplace
}

\author{
Victoria Giarrizzo \\ Doctora en Economía, Universidad de Buenos Aires, \\ Buenos Aires-Argentina, vgiarrizzo@gmail.com \\ Sandra Maceri \\ Doctora en Epistemología, Universidad de Buenos Aires, \\ Buenos Aires-Argentina, smaceri@conicet.gov.ar
}

\begin{abstract}
Cómo citar / How to cite
Giarrizzo, V. \& Maceri, S. (2019). ¿Egoístas o altruistas? Un experimento social para fomentar el comportamiento cooperativo en el mercado. Revista CEA, 5(10), 135-150. https://doi.org/10.22430/24223182.1318
\end{abstract}

Recibido: 15 de abril de 2019

Aceptado: 30 de junio de 2019

\section{Resumen}

Los mercados son sistemas de relaciones complejas donde muchas de las transacciones suelen ocurrir en el anonimato. La teoría económica dominante sostiene que las personas son seres naturalmente egoístas e individualistas y, por lo tanto, en esas interacciones, sean anónimas o no, siempre intentarán maximizar su nivel de ganancia, utilidad o bienestar, aunque para ello deban comportarse de manera poco cooperativa. Por tal razón, surge el interrogante: ¿̇es posible que los comportamientos altruistas se conviertan en prácticas comunes y generalizadas en las decisiones del mercado? Mediante un experimento social sencillo (experimento social propio) se muestra que no todos los individuos del mercado son egoístas y es frecuente que convivan con ellos personas con actitudes más altruistas. Así, se toma como caso hipotético de estudio el comportamiento de una empresa que decide su política de precios internos en una economía, cuando tiene la opción de exportar los mismos productos que vende en el mercado local al doble de su valor. La metodología de la investigación está fundamentada en una encuesta con diseño muestral probabilístico, bietápico por conglomerados, estratificado por nivel de ingresos. Finalmente, se muestran las intervenciones experimentales sutiles para lograr mayor cooperación de los individuos, obteniendo como resultado final, un incremento en las actitudes altruistas.

\footnotetext{
* Este artículo se deriva del proyecto titulado «¿Egoístas o altruistas? Un experimento social para fomentar el comportamiento cooperativo en el mercado» y ha sido financiado con recursos propios.
} 
Palabras clave: política económica, estudio del mercado, comportamiento social, cooperación económica.

\begin{abstract}
Markets are systems composed of complex relationships, and many transactions are usually conducted in anonymity. The dominant economic theory holds that people are completely selfish and individualistic beings. Therefore, in such interactions, anonymous or not, they always try to maximize their earnings, profit, or wellbeing, although, for that purpose, they may act in an uncooperative manner. As a consequence, a question arises: Can altruistic behaviors become common practice in the decisions of the marketplace? A hypothetical case was proposed to the participants in this study: A company must decide its domestic price policy when it can export, at double the price, the same products it is selling in the local market. Subsequently, a survey with a two-stage cluster probability sampling design stratified by income level was conducted. By means of a simple social experiment, this article shows that not all individuals in the market are selfish and people with more altruistic attitudes commonly coexist with them. Finally, subtle experimental interventions promoting more cooperation resulted in an increase in altruistic attitudes.
\end{abstract}

Keywords: Economic policy, market research, social behavior, economic cooperation.

\title{
1. INTRODUCCIÓN
}

La visión teórica dominante en Economía se sustenta en un postulado neoclásico controvertido que sostiene que los agentes económicos son seres naturalmente egoístas que buscan constantemente su mayor beneficio. Sobre esto se plantea un análisis económico de resolución de problemas mediosfines, dejando fuera del alcance otro tipo de comportamientos sociales posibles en el mercado (Tello, 2005). Este tipo de principios unidimensionales, que parecen guiar y justificar ciertas acciones económicas cotidianas, conllevan al menos dos dificultades: por un lado no contemplan las conductas de muchos individuos que, en la misma sociedad, toman sus decisiones guiados por principios más solidarios y altruistas, poniendo el bienestar colectivo por encima del bienestar individual; individuos que con mayor capacidad de empatía, se conmueven por los demás y están dispuestos a ceder o donar una porción de su bienestar para mejorar el del otro. Por otro lado, no se discute sobre la cuestión ética ni sobre las externalidades negativas que las decisiones para maximizarse de un individuo pueden generar respecto a otros actores de su misma sociedad (Gangadharan, Grossman, Komai \& Vecci, 2019).

La Economía supone esos postulados como principios básicos, los expresa en modelos lógicomatemáticos o lenguajes técnicos y, al omitir el debate basado en principios de justicia y equidad, excluye también el análisis de si sería o no conveniente modificar esas acciones e inducir entre los actores otro tipo de comportamientos y, en ese caso, estudiar cómo hacerlo. La teoría que respalda estos postulados es la del trabajo pionero de Adam Smith (1941), quien mediante una metáfora sostiene que existe una especie de mano invisible en el mercado que pone un orden espontáneo, haciendo que los hombres, en busca de su propio beneficio, terminen generando un mayor bienestar social. Así, por ejemplo, no sería menester preocuparse por temas como la especulación, los ajustes de precios o las tasas de ganancias excesivas que a veces definen las empresas, porque todos esos 
aspectos harían parte de un mercado que busca un equilibrio a partir de las acciones individuales de los hombres.

Respecto a estos postulados, un comportamiento frecuente en el mercado conocido como ley de oferta y demanda, versa que cuando baja la oferta de un producto, naturalmente suelen subir los precios. La teoría económica explica esa relación como una causalidad automática y como parte de la naturaleza del mercado: si hay escasez, es natural y esperable que el mercado suba el precio (Baer \& Kauw, 2016).

Sin embargo, una mirada menos individualista que contemple la dimensión ética de cada acción económica muestra que este tipo de comportamiento no es tan natural ( $y$, por lo tanto, no es tan necesario). En efecto, en múltiples ocasiones se observan situaciones donde escasea un producto por motivos que no ameritan un aumento de precios e igual suben, mientras la economía no se expide sobre la validez ética o social de esa acción (Harvey, 2013). Caben, pues, algunas preguntas a modo de ejemplos disparadores de índole ética: ¿está "bien", es correcto en el sentido de bueno, que suba el precio del colchón cuando hay una inundación en alguna zona de la ciudad afectada y, por ende, suba la demanda de ese producto? ¿Es comprensible, desde un el punto ético-moral, que si sube el tipo de cambio y el empresario gana más vendiendo afuera su producto que en el mercado local, lo aumente en el mercado interno para equiparar su precio con el de exportación? Cabe aclarar aquí, que no todo aumento de precio se debe a la escasez de los productos; es más, en el caso del experimento no se trata de escasez en sentido estricto sino de venta "quasi absoluta". Los precios, sin embargo, podrían aumentarse por parte del productor-vendedor, por una de las claves de este trabajo: el egoísmo y, en otros términos, la ambición del comportamiento privado.

Existen Estados que regulan más las acciones privadas para lograr una mejor coordinación entre los actores y, como consecuencia, evitar daños sobre los sectores vulnerables; también existen otros que regulan menos, generándose un mayor perjuicio a la sociedad porque las decisiones quedan en manos del mercado (Aguilar Villanueva, 2015). Pero en los dos casos suele predominar la idea que el mercado ajusta bajo su lógica, en la cual hay comportamientos que no son cuestionables; aun así, se pueden determinan grupos de individuos, tales como los presenta la teoría, individualistas, maximizadores o egoístas, y otros con un espíritu más cooperativo, social o altruista, que se ven perjudicados por cómo actúa el primer grupo.

El objetivo de este trabajo es presentar los resultados de un experimento social de diseño propio, planteando la situación hipotética de un fabricante de calefones, único productor que, favorecido por el tipo de cambio, comienza a exportar a precios más elevados sus productos y deberá decidir qué hacer con los precios de las unidades que le quedan para vender en el mercado local. Las alternativas dadas por nuestro experimento son: ¿los sube al mismo precio que recibe por su exportación, los sube más aprovechando su poder monopólico de mercado, los mantiene, los baja, o los regala/dona?

Sobre esa dinámica, se discute si los comportamientos altruistas pueden convertirse en prácticas comunes y generalizadas en las decisiones del mercado y de qué manera, tomando un caso muy sensible como es la formación de precios. También se evalúa el comportamiento teórico de los individuos que participaron del experimento en diferentes situaciones, mostrando la posibilidad de convertir comportamientos egoístas en altruistas. 
Se considera pertinente realizar la siguiente aclaración: podría considerarse que alguien altruista es, por definición, más justo en su comportamiento que alguien que no lo es. Sin embargo, esto es altamente discutible ya que depende del paradigma económico y filosófico en el que cada quien se sitúe. En este trabajo se tendrán en cuenta sólo los comportamientos altruistas, tal como se anticipa en el título. Por ejemplo, si para la teoría económica dominante los agentes son seres naturalmente egoístas e individualistas, eso podría hacer pensar que son seres humanos injustos en el sentido en que, si sólo buscan maximizar su propia utilidad, aun a costa de la ajena, la equidad no sería posible. Si se entiende la justicia como equidad (Rawls, 2002), se puede inferir que se está en frente de comportamientos injustos. Ahora bien, eso en el único caso en que se entienda la justicia como equidad. Sin embargo, Sen (2011) discute la revisión considerando que la idea de justicia requiere un componente empírico que Rawls desatiende. Dado pues que hay muchas otras maneras de entender justicia y conductas justas, este trabajo se centrará en el accionar altruista conforme anuncia su título. Ahora bien, cuando se lea "justo", como en el caso de "vendedor justo" por ejemplo, en las figuras 1 , 2 y 3 , se entiende por justicia la justicia seneana, a saber: el agente, en este caso el vendedor, ejerció su capacidad o libertad real de actuar con un plus de altruismo (Maceri, 2014). En el presente experimento es quien decide mantener el precio, tal como se irá comprendiendo conforme avance este escrito.

\section{MARCO TEÓRICO}

\section{Persona egoísta y persona altruista: las dos en una}

¿Es el individuo egoísta por su naturaleza o se vuelve egoísta en su interacción social? Desde que Thomas Hobbes inició ese debate, hacia 1651, mucho se ha discutido sobre el tema. El filósofo advertía que el estado natural del hombre no es pacífico ni solidario, sino que es egoísta y antisocial. "El hombre es un lobo para el hombre", fue quizá la frase que más se popularizó de su filosofía política de la naturaleza. Esta idea tuvo su contrincante en Jean-Jacques Rousseau (1762) que veía al hombre como un ser bueno por naturaleza, aunque inmerso en una sociedad donde cada uno lucha por su supervivencia y ambiciones, que corrompe y desvirtúa su naturaleza bondadosa. En esa línea, en un trabajo de Sussman y Cloninguer (2011) se plantea que el ser humano no es hostil o competitivo por naturaleza; por el contrario, es altruista, cooperador y social, pero en ocasiones se puede volver hostil o violento en determinadas condiciones, como cuando se ve sometido a presión, abusos, abandonos, o tiene alguna enfermedad mental.

Un experimento muy utilizado por los economistas y psicólogos sociales para estudiar las actitudes altruistas o egoístas de los individuos, es el juego del dictador (Carlsson, He \& Martinsson, 2009). Inicialmente propuesto por Kahneman en la década de 1980, es un juego donde participan dos jugadores que no tiene relación entre sí. Por un lado, el dictador, que recibe una cantidad de dinero inicial $(\$ 10)$ y al que se le pregunta cómo quiere repartirlo con el segundo jugador: el receptor, que recibirá lo que el dictador decida darle, que puede ser cero. Si los individuos fueran todos egoístas como predice el homo economicus, los dictadores se quedarían con el dinero y no repartirían nada. Pero lo que muestra el juego, que a lo largo de décadas se fue realizando en diferentes situaciones, es que muchos participantes son altruistas porque renuncian a una parte de sus ingresos para beneficiar a otros jugadores. En el juego original, en promedio el $70 \%$ de los dictadores dona algo, por un monto equivalente al $25 \%$ del total a repartir. Sin embargo, no todo es tan lineal. Variantes 
del mismo experimento mostraron que cuando el juego se realiza en el anonimato, los dictadores se muestran menos generosos que cuando se lleva a cabo en algún contexto visible (Dari-Mattiacci, Garoupa \& Gomez-Pomar, 2010). Lo contrario sucede cuando los dictadores reciben información sobre el receptor: se reduce la cantidad de dictadores que no donan nada y crece el porcentaje de quienes llegan a donar el 50 \% del total a repartir o más. Se replicaron, por ejemplo, una serie de experimentos donde se le informa al dictador que el receptor es la Cruz Roja de la localidad, lo que incrementa la propensión a repartir (Eckel \& Grossman, 1996). Pero ¿qué sucede cuando el dictador tiene la posibilidad de quitarle dinero al receptor? Esa pregunta se la hizo John List, profesor de la Universidad de Chicago en Estados Unidos e investigador del National Bureau of Economic Research, y comprobó que en ese caso el comportamiento del dictador cambia y se vuelve más egoísta.

En los últimos años el debate volvió a instalarse desde otra óptica: independientemente de si el individuo nace bueno o nace malo, o de si en un entorno es más generoso que en otro, podría (o no) ser o volverse solidario y altruista. Fueron las neurociencias las que se interesaron en este asunto. Un estudio reciente de la Universidad de Wisconsin-Madison a cargo de Davidson \& Begley (2012) confirma que podemos ser entrenados para sentir más empatía y ser más altruistas, compasivos y solidarios. Es decir, para recuperar la esencia de la naturaleza humana -suponiéndola buena al estilo de Rousseau, referido en el primer párrafo del presente apartado- o para poder pensar/actuar responsablemente en nuestros comportamientos poniéndonos en el lugar del otro. Si se concede que, de alguna manera, la forma de pensar del ser humano está determinada por factores externos, factores de la sociedad que determinan su conciencia, no sería insensato pensar en cómo conformar una matriz de pensamiento positiva a partir de esos factores externos.

Hay, por cierto, muchísimos juegos pertinentes en economía que suelen utilizarse. Para los fines de este trabajo basta con agregar, por ejemplo, el juego de la confianza que se trata de un juego entre dos personas en el que se logra observar el equilibrio, la cooperación y la posibilidad de deserción. En principio, cada jugador confía en el otro, aunque la traición entra también en juego. Pese a ello, el juego contempla la cooperación y, por lo tanto, el altruismo. No se profundizará en los detalles del juego, pero se resalta que los jugadores logran comprender que si ambos pierden un poco se puede redundar en el beneficio de los dos y en la pérdida de ninguno. Este juego no asegura que el ser humano se comporta altruistamente por naturaleza sino en virtud de su propio cálculo maximizador. Al fin y al cabo, es preferible confiar en el otro para el bien de sí mismo. Sin embargo, muchos autores han estudiado este juego de la confianza centrándose en la definición de tipos de jugadores tanto respecto de características intrínsecas como de factores externos (McCabe, Houser, Ryan, Smith \& Trouard, 2001); (Bolton \& Ockenfels, 2000); (Fehr \& Schmidt, 1999); (Rabin, 1993). Un aporte en el estudio de los factores externos lo hicieron Thaler y Sunstein (2008) con la "teoría del empujón" en donde se trata el concepto del "nudging" el cual es la manera de empujar a la población a tomar decisiones que las beneficien a largo plazo. Thaler demostró cómo ese "empujón" puede ayudar a las personas a ejercer un mejor autocontrol o a tomar mejores decisiones. Desde entonces, muchos países vienen trabajando en esa agenda, especialmente los países desarrollados. Un caso es el Behavioral Insights Team del Tesoro Británico que ha sistematizado el uso de esas herramientas a varias áreas de política para modificar patrones de comportamientos de la población. 


\section{¿Cooperar o maximizar?: un experimento sobre comportamientos de ajustes de precios}

Dado que se considera relevante e interesante ofrecer algunas reflexiones generales, en este apartado se muestran las condiciones iniciales sin distorsionar el experimento.

Según el enfoque economicista, los precios de los bienes y servicios son establecidos por el mercado, en un proceso de puja e intercambio donde operan otras variables, como la eficiencia y la competencia; allí el vendedor buscará maximizar su ganancia y el comprador maximizar su utilidad. Los precios del vendedor se establecen según sus costos de producción y su excedente bruto de explotación, dentro de un mercado donde operan las leyes de oferta y demanda, que son las que ponen límite a la ambición de ambas partes. La presión de la demanda o de la oferta de cada momento determinará que el precio baje o suba. Desde esa visión, donde hay muchos oferentes y demandantes, el mercado parece terminar siempre fijando un precio. Pero cuando se mira el mercado real, los precios por los que optan los vendedores no siempre son justos y el comportamiento del vendedor no siempre lo es. Ahora bien, ¿qué sucede, por ejemplo, con el empresario cuando tiene la posibilidad de fijar el precio que prefiera porque la necesidad del mercado lo avalará? Desde el racionalismo bajo certeza que impone el enfoque economicista, maximizará el precio (Maceri, 2009). Sin embargo, ese comportamiento podría estar acompañado de otras opciones, especialmente cuando se contempla la posibilidad de actuar de manera más altruista y solidaria, y en particular cuando de su decisión depende el bienestar de muchas familias heterogéneas, no sólo en los comportamientos sino en inteligencias, habilidades, y educación (Maceri, 2018).

Mucho se ha escrito sobre el modo de cooperar en distintos contextos. Por ejemplo, en el trabajo de Ortmann y Tichy (1999), se diseña un juego de laboratorio al estilo del dilema del prisionero, en el que se muestra cómo va variando la cooperación según el género, de acuerdo avanza el juego.

\section{METODOLOGÍA}

La encuesta que se presenta en este artículo fue realizada entre marzo y mayo de 2018 en cuatro tramos. Los meses y años de los cuatro tramos son los siguientes: al primer tramo le corresponde el mes de marzo del año 2018; al segundo tramo, marzo 2018, lo mismo para el tercer tramo; al cuarto tramo le corresponden los meses de abril y mayo del año 2018. Respecto al tamaño de la muestra, es de 500 en los primeros tres tramos y de 250 al cuarto tramo.

El diseño muestral es un diseño probabilístico bietápico por conglomerados, estratificado por nivel de ingresos. Se balanceó la muestra considerando un tercio de población de altos ingresos (nivel de gasto mensual del hogar mayor a \$55.000), un tercio de ingresos medios (nivel de gasto mensual entre 20 mil y 55 mil) y un tercio de bajos ingresos (menos de 20 mil), todos valores a marzo 2018. Como referencia: la canasta básica total (CBT) según INDEC, que delimita la línea de pobreza, para esa fecha es de $\$ 17.527$ en el caso de un hogar de cuatro miembros y el ingreso promedio del hogar, de $\$ 31.917$. Es importante mencionar que los ingresos corresponden a moneda argentina (peso argentino).

El diseño fue bietápico, ya que primero se seleccionó el aglomerado y luego los individuos dentro de cada aglomerado. Esta técnica representa correctamente el total de la población respecto de lo que 
se pretende mostrar, a saber, el comportamiento más o menos egoísta o más o menos altruista de la población argentina. Uno de los motivos más importantes para haber optado por este tipo de muestreo es el criterio decisional de los conglomerados por zonas geográficas; de ahí la determinación de las zonas geográficas relevadas: Avellaneda, Lanús y San Isidro en Gran Buenos Aires.

El método de relevamiento fue aleatorio, on-line, anónimo, vía cuestionario estructurado en la plataforma Facebook. Se utilizó esta plataforma por la cobertura de diferentes estratos de ingresos que tiene y porque permite segmentar la muestra por aglomerado, edad y otros criterios poblacionales. Se logró así seleccionar consumidores de distintos extractos sociales, con características sociodemográficas similares a las de los sujetos tomadores de decisión (empresarios) del planteo teórico-problemático.

Respecto del método presencial, con cuestionario estructurado, se seleccionaron las tres zonas cuyos niveles de ingresos conjuntos representan la media nacional. La selección de los encuestados fue también random, residentes de esos municipios y mayores de 21 años. El nivel de confiabilidad es de $95 \%$, mientras que el de error muestral es de $5 \%$. La población objetivo son consumidores mayores de 21 años, ya que en Argentina es la mayoría de edad legal, de cualquier género, cuya distribución de género es $53 \%$ de encuestados femenino y $47 \%$ masculino.

Como bien sostiene Smith (2002) el ideal metodológico de los experimentadores deriva una hipótesis comprobable (i), diseña un experimento (ii) que implementa (iii). Se efectúa una revisión (iv), la cual suele involucrar todo el sistema de hipótesis. El experimento diseñado es de construcción personal basado en la disyunción acerca del comportamiento egoísta o altruista en el mercado. El experimento no intenta precisar, ni por tanto mejorar ni establecer, un rango de precios justos, sino que se trata del comportamiento de los agentes $y$, en todo caso, el precio del producto que muestra el experimento está diseñado sólo con esa finalidad. Es un experimento social para fomentar el comportamiento cooperativo en el mercado. Ahora bien, se ha tenido en cuenta a Zizzo (2010) ya que consiste en un diseño experimental, que implica las instrucciones experimentales del autor, así como la variable de deseabilidad y la presión social. El enunciado es el siguiente:

Imaginemos que usted fabrica calefones, su empresa tiene capacidad de producir 500 unidades al mes y los vende todos por 1 peso cada uno, pero una empresa de Brasil decide comprarle 400 calefones al mes pagándole 2 pesos por unidad porque el tipo de cambio lo favorece. Al exportar 400 calefones, sólo le quedan 100 para vender en su país y puede venderlos al precio que desee porque no le dijimos: al menos hasta ahora, usted es el único productor del mercado. Desde ya, optamos por Brasil, pero pudimos haberlo hecho por cualquier otro país o, incluso, algún lugar en la misma Argentina: el asunto es que al vendedor le conviene dejar de venderle a su comarca. ¿Qué haría con esos 100 calefones que venderá en el mercado local? ¿Los seguiría vendiendo al mismo precio que antes? ¿Aprovecharía que hay menos calefones en el mercado local y aumenta el precio interno porque ahora su precio de referencia es $\$ 2$ por calefón? Usted sabe que hasta que aparezca un nuevo fabricante, aunque suba el valor, los vendería igual. ¿O decide bajar el precio compensando lo que gana de más en Brasil para beneficiar a sus clientes? 
Las preguntas anteriores se formularon en marzo de 2018 a 1750 personas distribuidas según sexo, niveles de ingresos y edad, para evaluar cómo sería su comportamiento si fuera responsable de formar algún precio, en este caso, de calefones, tal como se detallará más adelante, en la metodología. La teoría económica daría por descontado que, en esas condiciones, el valor de los 100 calefones debería aumentar. En la lógica de comportamiento individualista, si igual los vendería, por qué no aumentarlos y sacarles el mejor precio maximizando su ingreso. Para evaluar las respuestas se hizo la encuesta en cuatro opciones diferentes (ver Tabla 1). En el Grupo 1 (ver Figura 1), donde se relevaron a 500 personas, se presentó el caso hipotético del productor de calefones planteado, pero no se le dio opciones de respuestas. Se dejó abierto para que cada encuestado respondiera lo que deseaba.

En el Grupo 2 (ver Figura 2), con el mismo tamaño muestra, se le dio opciones cerradas de respuestas: a) sube el precio entre $\$ 1$ y $\$ 2 ;$ b) sube el precio a $\$ 2$; c) sube el precio a más de $\$ 2$; d) mantiene el precio en $\$ 1 ;$ o e) baja el precio. En el Grupo 3 (ver Figura 3) se repitió la opción del Grupo 2 sobre otras 500 personas, pero se agregó la opción 'donaría los calefones en el mercado local'. Una característica de estos tres grupos fue que la encuesta se realizó de manera on-line, y de forma anónima. Así, el encuestado se sentía en la libertad de responder sin la mirada de otro que lo juzgue en sus elecciones. En el Grupo 4 (ver Figura 4), sin embargo, se presentaron las mismas opciones que en el Grupo 3, pero la encuesta se realizó en forma presencial y sobre 250 casos (Ver Tabla 1).

Tabla 1. Ejercicios planteados sobre comportamientos de ajustes de precios Table 1. Price adjustment exercises

\begin{tabular}{|c|c|}
\hline Grupos & Opciones de respuestas \\
\hline Grupo 1 "Control" (encuesta anónima on-line) & Abiertas, cada encuestado responde lo que desea \\
\hline Grupo 2 (encuesta anónima on-line) & $\begin{array}{l}\text { a) sube el precio entre } \$ 1 \text { y } \$ 2 ; b \text { ) sube el precio a } \\
\$ 2 ; c \text { ) sube el precio a más de } \$ 2 ; d \text { ) mantiene el } \\
\text { precio en } \$ 1 ; \text { o) baja el precio }\end{array}$ \\
\hline Grupo 3 (encuesta anónima on-line) & $\begin{array}{l}\text { a) sube el precio entre } \$ 1 \text { y } \$ 2 ; b \text { ) sube el precio a } \\
\$ 2 ; c \text { ) sube el precio a más de } \$ 2 ; d \text { ) mantiene el } \\
\text { precio en } \$ 1 ; \text { o e) baja el precio; f) dona los } \\
\text { calefones al mercado local }\end{array}$ \\
\hline Grupo 4 (encuesta presencial semi-anónima) & $\begin{array}{l}\text { a) sube el precio entre } \$ 1 \text { y } \$ 2 ; b \text { ) sube el precio a } \\
\$ 2 ; c \text { ) sube el precio a más de } \$ 2 ; d \text { ) mantiene el } \\
\text { precio en } \$ 1 ; \text { o e) baja el precio; f) dona los } \\
\text { calefones al mercado local }\end{array}$ \\
\hline
\end{tabular}

Fuente: elaboración propia a partir de datos en Economática

Según las respuestas brindadas por los encuestados se formaron los siguientes tipos de vendedores: egoístas, altruistas o justos, según decidieran subir, bajar o donar; o bien, como una tercera posibilidad, mantener el precio. Es decir, tal como se adelantó en el último párrafo de la Introducción, estas son las definiciones: el vendedor es egoísta si sube el precio. El vendedor es altruista si baja el precio. El vendedor es justo si mantiene el precio o no lo mueve en absoluto, lo cual no significa que su precio sea el justo. La cuestión no es el precio como valor y/o cantidad sino el comportamiento.

\section{El modelo}

Una vez conformados los grupos y obtenidos los resultados, se procedieron a realizar las comparaciones entre el primero de ellos (Grupo 1 "Control") y los tres restantes (los grupos tratados). 
Utilizando una serie de modelos dicotómicos se puede estimar cuánto más aumentan o disminuyen las chances de subir o bajar los precios ante cada intervención. Los modelos binarios que se estimaron tienen la siguiente especificación funcional:

Donde:

$$
P\left(Y_{i}=1\right)=F\left(\beta_{0}+\beta_{1} T_{G}+\beta_{2} S+\beta_{3} e d u c+\beta_{4} e d a d\right)
$$

$Y_{i}=1:$ actitud "egoísta" (subir el precio).

$Y_{i}=0$ : actitud "altruista" (baja el precio, mantiene el precio, donar el calefón).

$T_{G}$ : variable categórica dummy que toma los valores $1,2,3$ o 4 dependiendo del grupo al cual pertenezca la observación. $G=1$ es el grupo control y $G=2,3$ o 4 son los grupos tratados.

$S$ : variable dummy que toma el valor " 1 " si la observación corresponde a una persona de género masculino y " 0 " si corresponde al género femenino

educ: variable categórica que toma el valor "1" si la observación corresponde a una persona con estudios primarios, " 2 " si la observación corresponde a una persona con estudios secundarios, " 3 " si la observación corresponde a una persona con estudios terciarios y " 4 " si la observación corresponde a una persona con estudios universitarios.

\section{RESULTADOS}

Los resultados del experimento arrojaron algunos matices. En el Grupo 1, el 44,4 \% de los que contestaron la pregunta mostraron un comportamiento 'egoísta' y anticiparon que subirían los precios. Pero no todos tuvieron una lógica oportunista frente a situaciones de ese tipo, un 7,0 \% de los que respondieron la encuesta aseguraron que tendrían un comportamiento altruista y bajarían los precios. Aprovechando las ganancias extras obtenidas en Brasil, ofrecerían mejores condiciones a sus clientes locales. El sentimiento altruista está en muchos individuos que no siempre buscan maximizar sus ganancias permanentemente. Lo mismo sucedió con el 48,5 \% restante, que dijo que sostendría los precios en los mismos valores. En resumen, un 55,5\% actuaría de una manera 'altruista', manteniendo o bajando los precios.

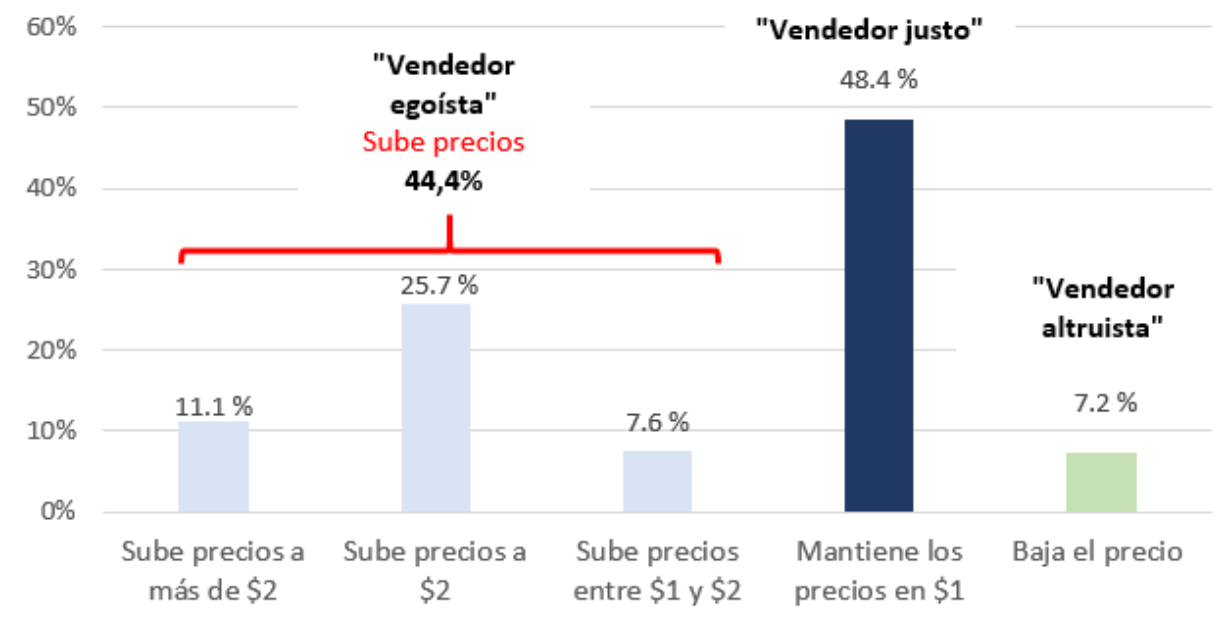

Figura 1. con respuesta abierta. Muestra: 500 individuos. El test del calefón ¿Subir o bajar los precios? Figure 1. Open-ended question. Sample: 500 individuals. Water heater test: Raise or lower the prices? Fuente: elaboración propia. 
En el Grupo 2 (ver Figura 2), cuando a los individuos se les dieron respuestas cerradas donde explícitamente se incluyó la opción 'bajar' precios, siguiendo el modelo planteado en el punto anterior, la probabilidad de que la gente subiera el precio disminuyó un 3 \% en relación al Grupo 1 (Control). En otras palabras, la probabilidad de que existan comportamientos egoístas se redujo, pero muy levemente, porque el resultado no fue estadísticamente significativo.

En porcentajes, el 41,6 \% de los que contestaron la pregunta dijeron que subirían los precios, es decir, se redujo en 2,8 puntos porcentuales la proporción de gente que subiría los precios. Pero se redujo también 2,5 puntos la proporción de empresas que mantendría el precio. En cambio, subió 5,4 puntos la cantidad de gente que bajaría el precio. De alguna manera los resultados indican que al agregar la opción bajar el precio, más gente comenzó a pensar que hay decisiones más cooperativas que se pueden tomar en un escenario así. Frente al Grupo 1, en el Grupo 2 el 58,4 \% mantendría o bajaría los precios, 2,9 puntos porcentuales más que en el Grupo 1.

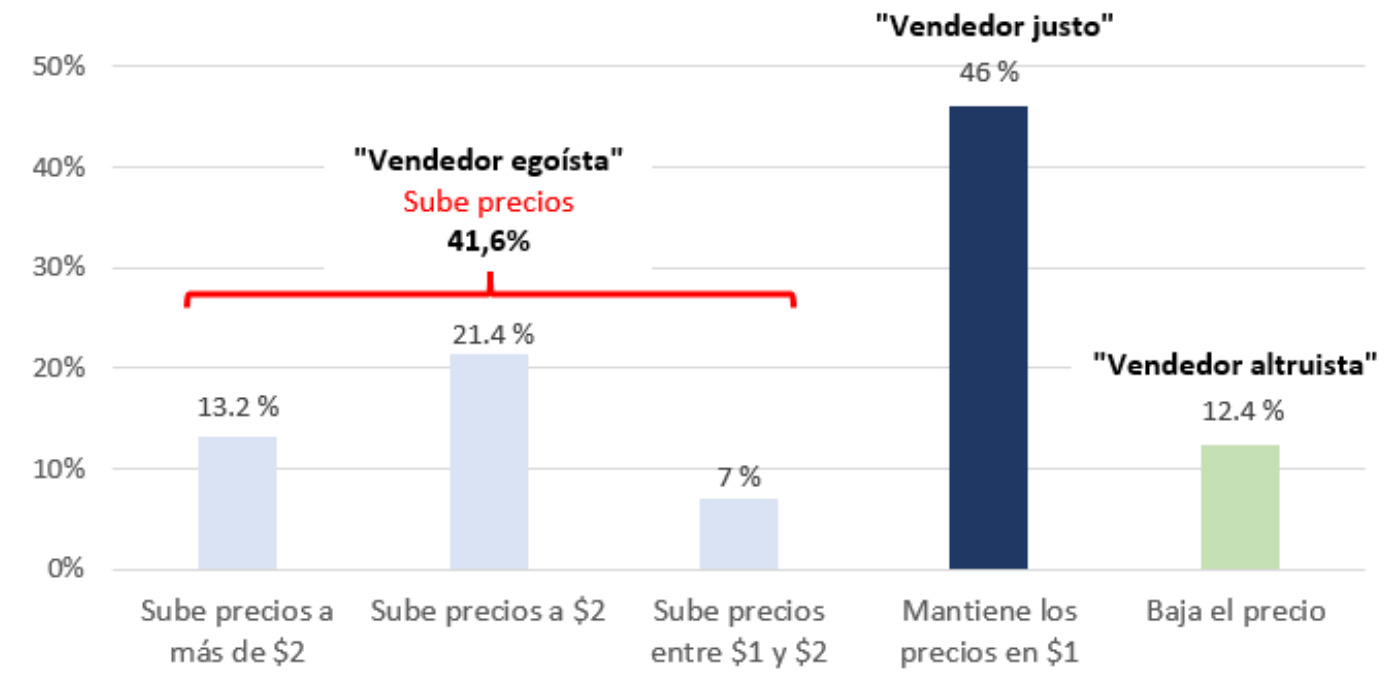

Figura 2. con pregunta cerrada. Muestra: 500 individuos. El test del calefón ¿Subir o bajar los precios?

Figure 2. Closed-ended question. Sample: 500 individuals. Water heater test: Raise or lower the prices? Fuente: elaboración propia.

Lo más significativo en materia de cambios en el comportamiento se observó en el Grupo 3 (ver Figura 3), cuando se dieron opciones cerradas de respuestas, pero se agregó la opción 'donar los calefones'. Agregar esa dimensión generó una apertura mayor en el pensamiento de las opciones posibles y mucha gente que no se había planteado esa posibilidad, la comenzó a pensar. Así, en el Grupo 3, la probabilidad de tener una actitud egoísta y subir el precio disminuyó 8,6 \% frente al Grupo 1 , con un alto nivel de significancia estadística. Específicamente, al agregar la opción 'donar', el porcentaje de personas que subiría el precio bajó a 34,9 \%, 9,5 puntos menos que en el G1. La cantidad de gente que mantendría el precio se mantuvo relativamente estable $(47,2 \%$ vs $48,4 \%$ en el G1). Pero lo que creció considerablemente fue la proporción de gente que bajaría o donaría el calefón: 17,9\%, con un $6 \%$ de donantes. En resumen, el 65,1 \% de la gente mantendría, bajaría o regalaría el calefón (vs 55,5\% en el G1). 


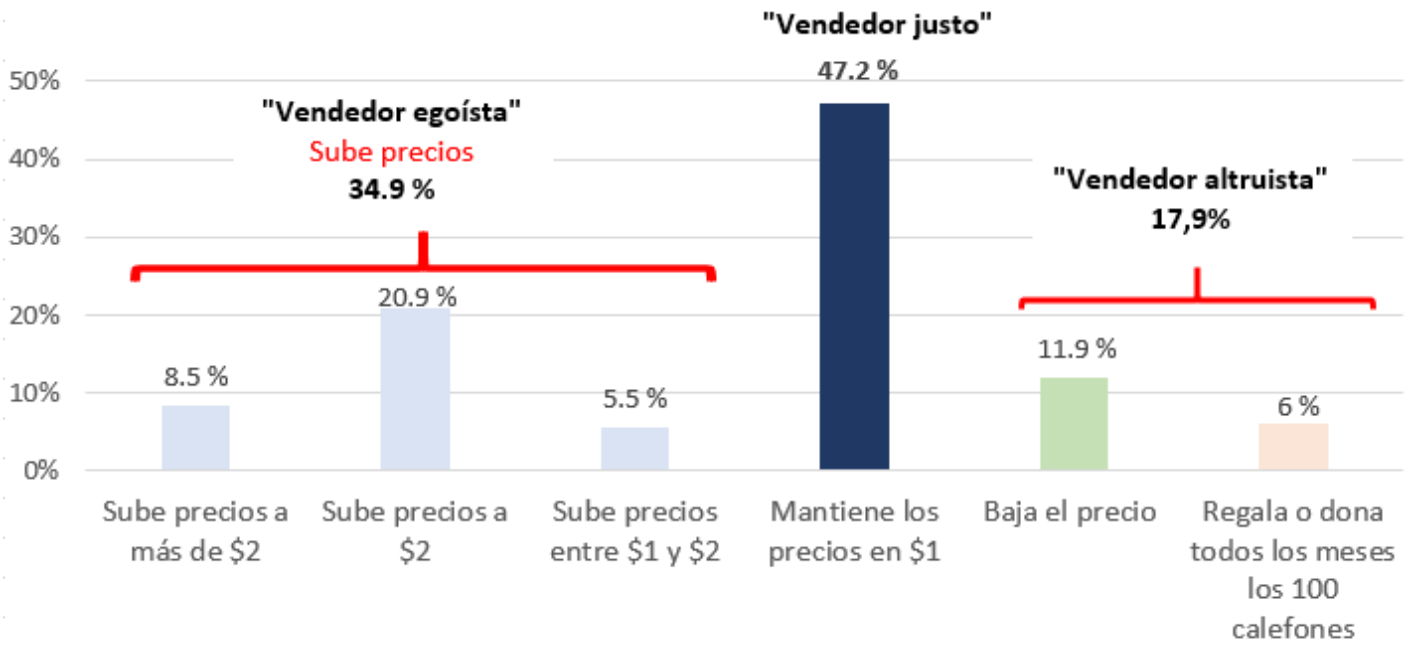

Figura 3. con preguntas cerradas y opción donar. Muestra: 500 individuos. El test del calefón ¿Subir o bajar los precios?

Figure 3. Closed-ended questions and option to donate. Sample: 500 individuals. Water heater test: Raise or lower the prices?

Fuente: elaboración propia.

\section{El hombre bajo el anillo de Giges: ¿qué sucede cuando nos miran?}

¿Cómo actuaríamos si supiésemos que absolutamente nadie nos está observando? ¿Cómo actuaríamos si sabemos que nadie podría juzgar nuestra conducta y, por tanto, no habría castigo posible? Se suele actuar frente a testigos, es decir, se suele actuar con uno o varios observadores probablemente casuales donde se pone en juego, por parte del que observa, la posibilidad de una sentencia valorativa sobre la conducta. Por ser observados, por el hecho de nuestra conducta se sepa, hay posibilidad de castigo. La pregunta es si actuaría del mismo modo con testigos que sin ellos ¿variaría la conducta de cualquier individuo según sea o no observado y, entonces, juzgado y, quizás, castigado?

Este tipo de situaciones teóricas remiten al mito del anillo de Giges, donde se ilustra cómo poder actuar sin testigos habilita la acción injusta. Giges era un pastor con un anillo de oro que tenía el poder de volverlo invisible cada vez que lo daba vuelta, después de reiteradas comprobaciones, Giges supo sobre el poder del anillo. Con el anillo en su mano, decidió y logró apoderarse del reino de Lidia. Llevando el mito a un extremo, hay una interpretación que sostiene que la acción injusta es propia de la naturaleza del hombre; así, la mirada del otro opera como un freno a la conducta irremediablemente injusta. En el mito el pastor Giges dio rienda suelta a su naturaleza. En La República (II, 359a - 360d) Platón narra la leyenda del anillo de Giges insertándola en el tema de las acciones justas o injustas. El personaje Glaucón recurre al mito para, precisamente, ejemplificar su teoría de que todas las personas son injustas por naturaleza. Si actúan de manera justa esto es sólo por temor al castigo. Si fuéramos invisibles a la ley como Giges con el anillo, seríamos injustos por nuestra naturaleza. Por esto, no hay diferencia alguna entre quienes actúan mejor o peor, más justa o injustamente, tal como expone el mito del anillo de Giges. 
En el experimento social diseñado llevado a cabo sucedió algo similar: las conductas, en este caso, la toma de decisiones sobre donar los calefones, varían según los encuestados han respondido frente a testigos o no. Como en el experimento anterior, se repitió la encuesta, pero esta vez con la mirada presencial de una encuestadora. Se realizaron 250 encuestas con el mismo ejercicio anterior, pero ahora la encuestadora le daba la opción de donar y le explicaba las ventajas de esa alternativa. En este caso, la probabilidad de tener un comportamiento egoísta y subir el precio disminuyó $25,4 \%$ frente al Grupo 1, con un elevado nivel de significancia estadística.

El resumen de los resultados estadísticos mostró que, en este caso, el 26,4 \% de los encuestados eligió 'donar el calefón', frente a sólo el 6 \% que lo hizo en la encuesta anónima (G3) y sin un sujeto que persuada argumentalmente. Bajo la mirada del otro, muchos encuestados posiblemente se sintieron en la obligación semi- 'moral' de donar el calefón. Solo el 17,6 \% eligió la opción subir el precio. Por ello, en todo el trabajo los resultados son los que corresponden al experimento que hemos diseñado y no a planteamientos de economía internacional; de ahí que no nos hayamos extendido en ello.

La mirada del otro, junto a la generación de consciencia y empatía, despertaron el sentimiento altruista del encuestado (ver Tabla 2).

Tabla 2. Resultados en los ejercicios planteados sobre comportamientos

Table 2. Results of price adjustment exercises

\begin{tabular}{|c|c|c|c|}
\hline Grupos & Sube el precio & $\begin{array}{c}\text { Mantiene, baja } \\
\text { o regala }\end{array}$ & Opciones de respuestas \\
\hline Grupo 1 & $44,4 \%$ & $55,5 \%$ & Abiertas, cada encuestado responde lo que desea \\
\hline Grupo 2 & $41,6 \%$ & $58,4 \%$ & $\begin{array}{l}\text { a) sube el precio entre } \$ 1 \text { y } \$ 2 \\
\text { b) sube el precio a } \$ 2 \\
\text { c) sube el precio a más de } \$ 2 \\
\text { d) mantiene el precio en } \$ 1 \\
\text { e) baja el precio }\end{array}$ \\
\hline Grupo 3 & $34,9 \%$ & $65,1 \%$ & $\begin{array}{l}\text { a) sube el precio entre } \$ 1 \text { y } \$ 2 \\
\text { b) sube el precio a } \$ 2 \\
\text { c) sube el precio a más de } \$ 2 \\
\text { d) mantiene el precio en } \$ 1 \\
\text { e) baja el precio } \\
\text { f) dona los calefones al mercado local }\end{array}$ \\
\hline Grupo 4 & $17,6 \%$ & $82,4 \%$ & $\begin{array}{l}\text { a) sube el precio entre } \$ 1 \text { y } \$ 2 \\
\text { b) sube el precio a } \$ 2 \\
\text { c) sube el precio a más de } \$ 2 \\
\text { d) mantiene el precio en } \$ 1 \\
\text { e) baja el precio } \\
\text { f) dona los calefones al mercado local }\end{array}$ \\
\hline
\end{tabular}

Fuente: elaboración propia.

Un dato adicional que arroja el modelo dicotómico utilizado es que, en el conjunto de los datos analizados en las cuatro encuestas, ser hombre parece aumentar en un 8,6 \% la probabilidad de ser egoísta (subir el precio), con elevado nivel de significancia estadística. En cambio, no hay diferencias significativas en el comportamiento según la edad y el nivel educativo de los respondientes (Ver tabla $3)$. 
Tabla 3. Probabilidad de que el individuo adopte una actitud "egoísta": efectos marginales estimados Tabla 3. Probability that an individual will adopt a "selfish" attitude: estimated marginal effects

\begin{tabular}{lc}
\hline Grupo 2 & $\begin{array}{c}\text { Modelo } \\
\text { Logit }\end{array}$ \\
\hline & $-0,030^{*}$ \\
\hline Grupo 3 & $(0,039)$ \\
\hline & $-0,086^{* *}$ \\
\hline Grupo 4 & $(0,038)$ \\
\hline & $-0.254^{* * *}$ \\
\hline Género & $(0,033)$ \\
\hline Log-likelihood & 0,086 \\
\hline Pseudo R2 & 0,030 \\
\hline$N$ & $-614,9$ \\
\hline & 0,0455 \\
\hline
\end{tabular}

\section{DISCUSIÓN}

Ahora bien, el cambio de conducta referido en el apartado anterior no ocurre espontáneamente, sucede con una especie de guía, tal como se desprende de nuestro experimento social. De ese ejercicio podría inferirse que, si bien los seres humanos no tienden a comportamientos altruistas en una primera instancia, muchos sí lo hacen si se les ofrecen opciones o si están frente a un observador externo (anillo de Giges), porque de alguna manera comprenden que su actuar no es del todo correcto. De este modo, la disyunción exclusiva "egoístas o altruistas" sería, en rigor, una disyunción inclusiva. Si no por naturaleza, sí por un modo de trocar conductas o por el pudor de un testigo, el ser humano no parece ser absolutamente egoísta, puesto que, con determinados mensajes subliminales, se logra una mayor cooperación en los comportamientos del mercado.

Persona egoísta y persona altruista: las dos en una. Se contempla la posibilidad de que ningún agente decisor, en este caso el vendedor, sea absolutamente egoísta. Sin embargo, es sólo una posibilidad muy discutible y sólo a través de dos vías: o por la observación de un testigo externo que podría juzgarlo como egoísta o a través de "pequeños empujones" (Gneezy \& List, 2014).

La intención del experimento es mostrar que los comportamientos egoístas pueden dejar de serlo, o al menos debilitarse, acercándose a conductas más altruistas. Sin embargo, ¿qué tan lícito resulta que el comportamiento amengüe su egoísmo sólo porque alguien más lo mira, lo observa (anillo de Giges)? En el mismo sentido, ¿qué tan válido es actuar menos egoístamente por "pequeños empujones" ("nudging")? No se sabe si el ser humano nace egoísta o no, es una antigua discusión desde Rousseau versus Hobbes. Aunque el juego del dictador parece probar que si el ser humano nace egoísta podría volverse menos egoísta, disminuyendo su supuesta esencia de homo economicus, las diferentes versiones del juego muestran resultados muy distintos. Sin embargo, es interesante remarcar la versión en la que el mismo dictador, que lograba ser más o menos altruista, da una vuelta tal en una de sus decisiones y se torna más egoísta que al principio del juego.

\footnotetext{
${ }^{1}$ Errores standard robustos entre paréntesis: ${ }^{* * *} p<0.01,{ }^{* *} p<0.05,{ }^{*} p<0.1$
} 
El experimento es también una forma de juego tal que toma partido contra el comportamiento del homo economicus e intenta -es discutible si lo logra o no- revertirlo a un ser no maximizador de su propio beneficio, menos individualista o egoísta con un espíritu más cooperativo, social o altruista.

Para finalizar, se ofrece la siguiente reflexión, tan discutible como interesante, basada en Edipo Rey de Sófocles: en el experimento quien compra más caro ¿es víctima del vendedor llamado "egoísta"? En el rol del comprador, ¿̇le cabe alguna responsabilidad, pudo haber hecho algo como por ejemplo tomar algún tipo de decisión a su favor? En un mercado signado por la valoración supina de las libertades individuales, surge la duda si, dada la situación del vendedor egoísta, el comprador podría ser condición de posibilidad o, al menos, colaborador de ese egoísmo. Bien podría diseñarse un experimento con los comportamientos de los compradores y en él notar si sus conductas contribuyen o no al altruismo o el egoísmo del vendedor. Si se entiende que el mercado -y la sociedad toda- no es un conglomerado de partes sino un conjunto interactivo, merecería el esfuerzo reflexionar sobre la otra parte del experimento. En ese caso, ya no el testigo externo ni la teoría del empujón serían viables para variar la conducta del comprador, sino el comportamiento mismo de los compradores. El presente trabajo, obviamente, se centró en el comportamiento del vendedor, aunque sería atractiva una discusión futura desde la otra parte.

\section{CONCLUSIONES}

Los comportamientos sociales muestran patrones diferentes, que pueden agruparse en categorías según sean más justos, más solidarios, colaborativos o egoístas. La teoría económica predominante suele contemplar con facilidad a este último grupo, pero dice menos sobre los otros. Posiblemente por la creencia de que los mercados pueden lograr equilibrios dejando que predomine el espíritu egoísta o individualista, no se discute si esas acciones son buenas o malas, o su efecto sobre la sociedad. Sin embargo, la evidencia muchas veces marca la necesidad de revertir esos patrones conductuales para lograr equilibrios más justos y equitativos, porque cuando el individualismo se generaliza sobre el mercado, el impacto sobre los actores más vulnerables o sobre aquellos que se mueven con otro tipo de lógica conductual, puede ser fuerte. Casos como los abusos de precios, la evasión fiscal, el trabajo informal u otras conductas desleales, son explicadas por la predominancia de comportamientos egoístas.

Este trabajo se propuso mostrar que, aun cuando en los mercados prevalecen los actores egoístas, esos patrones de comportamientos pueden modificarse cuando se les muestra a esos individuos otras opciones posibles que escapen a la racionalidad bajo certeza del mercado. Así, los comportamientos egoístas se pueden tornar menos egoístas y hasta altruistas. El experimento social llevado a cado lo pone de manifiesto, mostrando cómo este cambio de conducta es posible sin necesidad de entrar en el debate sobre si el ser humano es altruista por naturaleza o egoísta. Se arroja evidencia de cómo las decisiones mayoritariamente egoístas, ya sea por naturaleza o por opción de diferentes tipos, pueden ser revertidas a descomes cada vez menos egoístas hasta llegar, quizás, a las altruistas.

Sin duda la metodología tuvo limitaciones. Como todo relevamiento y experimento social, este tipo de técnicas tiene sus limitaciones, una de ellas es el tamaño muestral que, si bien se buscó obtener la mayor representatividad, por cuestiones presupuestarias, la muestra podría no tener la robustez necesaria para extraer resultados concluyentes. De todas formas, se considera que es una buena 
aproximación para obtener evidencia y cuantificar comportamientos que, de lo contrario, las apreciaciones serían intuitivas y/o retóricas.

\section{REFERENCIAS}

Aguilar Villanueva, L. F. (2015). Gobernanza y gestión pública. Recuperado de https://bit.ly/2MlgeDF

Baer, L. \& Kauw, M. (2016). Mercado inmobiliario y acceso a la vivienda formal en la Ciudad de Buenos Aires, y su contexto metropolitano, entre 2003 y 2013. EURE (Santiago), 42(126), 5-25. https://dx.doi.org/10.4067/S0250-71612016000200001

Bolton, G. E. \& Ockenfels, A. (2000). ERC: A theory of equity, reciprocity, and competition. The American Economic Review, 90(1), 166-193. https://doi.org/10.1257/aer.90.1.166

Carlsson, F., He, H. \& Martinsson, P. (2009). Easy come, easy go: the role of windfall money in lab and field experiments. Recuperado de https://gupea.ub.gu.se/handle/2077/20794

Dari-Mattiacci, G., Garoupa, N. \& Gomez-Pomar, F. (2010). State Liability. European Review of Private Law, 18, 773-811. Recuperado de https://scholarship.law.tamu.edu/facscholar/535?utm source=scholarship.law.tamu.edu \%2Ffacscholar\%2F535\&utm medium=PDF\&utm campaign=PDFCoverPages

Davidson, R. J. \& Begley, S. (2012). The emotional life of your brain: How its unique patterns affect the way you think, feel, and live - and how you can change them. Wisconsin: WisconsinMadison University Press.

Eckel, C. C. \& Grossman, P. J. (1996). Altruism in Anonymous Dictator Games. Games and economic behavior, 16(2), 181-191. https://doi.org/10.1006/game.1996.0081

Fehr, E. \& Schmidt, K. M., (1999). A Theory of Fairness, Competition, and Cooperation. The Quarterly Journal of Economics, 114(3), 817-868. https://doi.org/10.1162/003355399556151

Gangadharan, L., Grossman, P. J., Komai Molle, M., \& Vecci, J. (2019). Impact of Social Identity and Inequality on Antisocial Behaviour. European Economic Review, 119, 199-215 https://doi.org/10.1016/j.euroecorev.2019.07.004

Gneezy, U. \& List, J. (2014). Lo que importa es el porqué: los motivos económicos ocultos de nuestras acciones. Barcelona: Empresa Activa.

Harvey, D. (2013). Ciudades rebeldes. Del derecho de la ciudad a la revolución urbana. Recuperado de https://bit.ly/2Yrilap

Kahneman, D., Knetsch, J., Thaler, R. (1986). Fairness and the assumptions of economics. The Journal of Business, 59(4), 285-300. Recuperado de https://www.jstor.org/stable/2352761 
Maceri, S. (2009). ¿Qué significa ser racional? Sobre el concepto epistemológico de racionalidad crítica. En II Congreso Internacional de Investigación de la Facultad de Psicología de la Universidad Nacional de La Plata, La Plata, Argentina. Recuperado de http://sedici.unlp.edu.ar/handle/10915/17228

Maceri, S. (2014). El bienestar comunal como alternativa al fracaso del concepto neoclásico de bienestar. Revista Internacional de Ciencias Sociales, 3(1), 25-37. Recuperado de https://journals.epistemopolis.org/index.php/csociales/article/view/1134

Maceri, S. (2018). ¿La perseverancia ¿paga lo mismo que la inteligencia? Habilidades cognitivasno cognitivas, comportamientos, educación y maquiavelismo. Buenos Aires: Ediciones cooperativas.

McCabe, K., Houser, D., Ryan, L., Smith, V. \& Trouard, T. (2001). A functional imaging study of cooperation in two-person reciprocal exchange. Proceedings of the National Academy of Sciences, 98(20), 11832-11835. https://doi.org/10.1073/pnas.211415698

Ortmann, A. \& Tichy, L. K. (1999). Gender differences in the laboratory: evidence from prisoner's dilemma games. Journal of Economic Behavior \& Organization, 39(3), 327-339. https://doi.org/10.1016/S0167-2681(99)00038-4

Rabin, M. (1993). Incorporating Fairness into Game Theory and Economics. The American Economic Review, 83(5), 1281-1302. Recuperado de https://www.jstor.org/stable/2117561

Rawls, J. (Ed). (2002). Justice as Fairness: A Restatement. Cambridge: Harvard University Press.

Sen, A. K. (2011) The Idea of Justice. Cambridge: Harvard University Press.

Smith, A. (1941). Teoría de los sentimientos morales. Colegio de México. https://doi.org/10.2307/i.ctv233mi3

Smith, V. L. (2002). Method in Experiment: Rhetoric and reality. Experimental Economics, 5(2), 91-110. https://doi.org/10.1023/A:1020330820698

Sussman, R. W. \& Cloninger, C. R. (Eds.) (2011). Origins of altruism and Cooperation. Berlín: Springer Science \& Business Media.

Tello, E. (2005). La Historia cuenta: del crecimiento económico al desarrollo humano sostenible. Recuperado de https://bit.ly/2YgVSOG

Thaler, R. H. \& Sunstein, C. R. (2008). Nudge: Improving decisions about health, wealth, and happiness. New Haven: Yale University Press.

Zizzo, D. J. (2010). Experimenter demand effects in economic experiments. Experimental Economics, 13(1), 75-98. https://doi.org/10.1007/s10683-009-9230-z 